\title{
Leaching behaviour of impurities in waste gypsum board
}

\author{
M. Tafu \& T. Chohji \\ Department of Ecomaterials Engineering, \\ Toyama National College of Technology, Japan
}

\begin{abstract}
Gypsum board is widely used as a building material in many countries. In Japan, three million tons of gypsum board is manufactured for building construction, and about one million tons of waste gypsum board is generated from demolition work. Most waste gypsum board has been placed in landfill sites. Recycle processes of waste gypsum boards are needed because of a lack of landfill capacity. To improve the recycle ratio, waste gypsum board is recycled not only into gypsum board but also into other products, such as roadbed materials. Waste gypsum board must be clean from contaminants for recycling. Contaminants such as wood, plastic, metal and asphalt in waste gypsum board are separated from it. However, waste gypsum board contains some chemical impurities in it. When the waste gypsum board is applied to roadbed materials, the impurities can leach from gypsum into ground water; therefore, leaching behaviour of impurities in gypsum is important. Chemical equilibrium tells us important useful information about how to dissolve gypsum. In this study, we developed a novel method for estimating leaching behaviour of waste gypsum based on the chemical equilibrium and experimental studies. From results of chemical equilibrium assessments, it is apparent that gypsum turns to calcium carbonate in a solution containing carbonate ion at alkaline $\mathrm{pH}$, and releases sulfuric ion and various impurities. Experiment results showed that waste gypsum board easily dissolved and leached various impurities in the alkaline solution by the addition of carbon dioxide gas.
\end{abstract}

Keywords: gypsum board, impurities, chemical equilibrium, recycle. 


\section{Introduction}

Gypsum board is widely used as a building material in many countries. The gypsum board is made from natural gypsum rock and chemical gypsum. Gypsum is a soft mineral composed of calcium sulphate dehydrate, with the chemical formula $\mathrm{CaSO}_{4} \cdot 2 \mathrm{H}_{2} \mathrm{O}$. Chemical gypsum encompasses all by-product and co-product gypsum produced from various industries. These industries include flue-gas desulphurization in electrical power plants, phosphoric acid production plants, titanium oxide production plants and fluoric acid production plants. These chemical gypsums are named flue-gas desulphurization gypsum, phosphogypsum, titan gypsum and fluoro gypsum respectively. The chemical gypsums contain various impurities, for example phosphoric acid is produced from phosphate rock. Fluorides such as sodium fluoride $(\mathrm{NaF})$, calcium fluoride $\left(\mathrm{CaF}_{2}\right)$ and sodium hexafluorosilicate $\left(\mathrm{Na}_{2} \mathrm{SiF}_{6}\right)$ [1] are present as impurities in phosphogypsum because the main component of phosphate rock is fluorapatite $\left(\mathrm{FAp}, \mathrm{Ca}_{10}\left(\mathrm{PO}_{4}\right)_{6} \mathrm{~F}_{2}\right)[2]$.

In Japan, three million tons of gypsum board is manufactured for the construction trade, and about one million tons of waste gypsum board is generated from demolition work. Most waste gypsum board is placed in landfill sites. Recycling processes of waste gypsum boards are needed because of a lack of landfill capacity. To improve the recycle ratio, waste gypsum board is recycled not only to gypsum board but also into other products, such as roadbed materials. Waste gypsum board must be clean from contaminants for recycling. Contaminants such as wood, plastic, metal, and asphalt in waste gypsum board must be removed. However, waste gypsum board contains some chemical impurities in it. When the waste gypsum board is applied to roadbed materials, the impurities can leach into ground water. In Japan, regulations of concerning fluoride in water and soil are currently being strengthened; therefore leaching behaviour of impurities in gypsum is important. Chemical equilibrium tells us important useful information about how to dissolve gypsum. In this study, we developed a novel method for estimating leaching behaviour of waste gypsum based on the chemical equilibrium and experimental studies.

\section{Approach to the study}

The dissolution mechanism of gypsum in water is assessed by the chemical equilibrium theory. The simplest reaction is expressed as the following equation [3].

$$
\mathrm{CaSO} 4.2 \mathrm{H} 2 \mathrm{O} \rightleftharpoons \mathrm{Ca}^{2+}+\mathrm{SO}_{4}{ }^{2-}+2 \mathrm{H}_{2} \mathrm{O}
$$

When sulphate ion is put in stronger acid, it reacts with hydrogen ion to shift to hydrosulfate ion as follow.

$$
\mathrm{SO}_{4}^{2-}+\mathrm{H}^{+} \rightleftharpoons \mathrm{HSO}_{4-}
$$


The result of this is the concentration of sulphate ion decreases. When concentration of the sulphate ion decreases in eqn (1), the gypsum becomes dissolved more in response.

The partial pressure of carbon dioxide in the soil is higher than it is in the atmosphere [4]. The carbon dioxide in the soil layer reacts with soil water to form dissolved inorganic carbonate ions through the following reactions.

$$
\begin{aligned}
\text { Soil- } \mathrm{CO}_{2}+\mathrm{H}_{2} \mathrm{O} & \rightleftharpoons \mathrm{CO}_{2} \cdot \mathrm{H}_{2} \mathrm{O} \\
\mathrm{CO}_{2} \cdot \mathrm{H}_{2} \mathrm{O} & =\mathrm{HCO}_{3-}+\mathrm{H}^{+} \\
\mathrm{HCO}_{3-} & =\mathrm{CO}_{3}{ }^{2-}+\mathrm{H}^{+}
\end{aligned}
$$

The carbonate ion can react with calcium ion in gypsum to form insoluble calcium carbonate.

$$
\mathrm{CO}_{3}{ }^{2-}+\mathrm{Ca}^{2+} \rightleftharpoons \mathrm{CaCO}_{3}
$$

When carbon dioxide concentration in the soil is higher, the equilibriums in eqns (3) to (5) shift to right, and carbonate ion concentration in the soil water is increased. Increasing the carbonate ion concentration makes the equilibrium in eqn (6) shift to the right, and decreases the free calcium ion concentration. Subsequently the equilibrium in eqn (1) shifts to the right, resulting in more gypsum dissolving.

Figure 1 shows the calculated solubility of gypsum in solutions under various partial pressures of carbon dioxide $\left(p \mathrm{CO}_{2}\right)$, based on chemical equilibrium. This figure shows that gypsum can be dissolved and translated to calcium carbonate above $\mathrm{pH} 7.8$ on $p \mathrm{CO}_{2}=3.7 \times 10^{-4}$ and $\mathrm{pH} 6.8$ on $p \mathrm{CO}_{2}=0.03$.

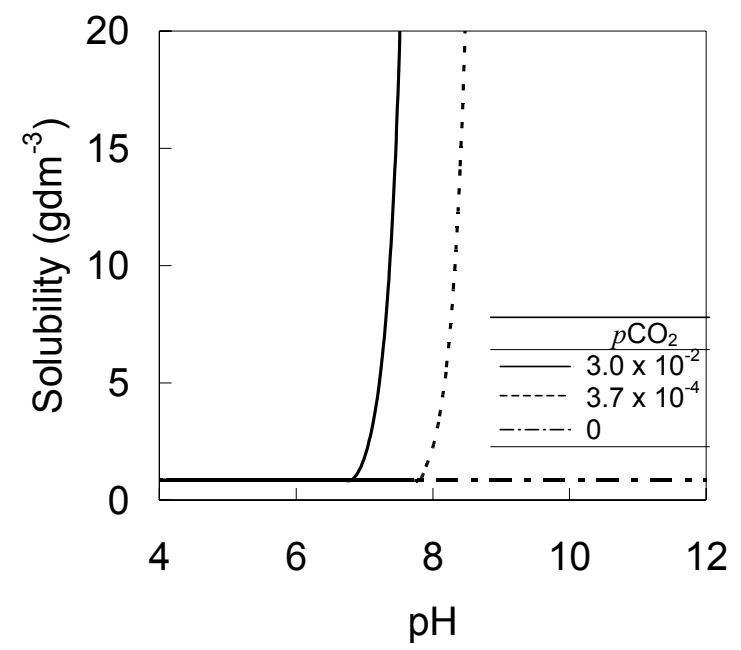

Figure 1: Dependency of the solubility of gypsum on $\mathrm{pH}$ in the presence of various partial pressures of carbon dioxide $\left(p \mathrm{CO}_{2}\right)$. 


\section{Experiment}

\subsection{Reagents}

The gypsum used was a guaranteed reagent grade (Wako Pure Chemical Co. Ltd., Japan) for basic study. Two chemical gypsums were used in this study. Ionexchanged water and ultra-purified water.

\subsection{The procedure of experiments}

\subsubsection{Leaching behaviour of gypsum in water}

We evaluated the leaching behaviour of gypsum in the water by a method described previously [5]. Figure 2 shows a schematic diagram of the experimental procedure. $1.0 \mathrm{~g}$ of gypsum sample was added to $30 \mathrm{~cm}^{3}$ of ultrapurified water in a polypropylene bottle. The mixture was shaken in a reciprocal shaker (Type NR-1, TAITEC, Japan) at room temperature. The solution was filtered with a $0.40 \mu \mathrm{m}$ membrane filter. The sample remaining on the filter was again mixed with $30 \mathrm{~cm}^{3}$ of water, this process was repeated 5 times. The concentrations of calcium and sulphur elements in the solutions were measured by induction coupled plasma atomic emission spectroscopy (ICP-AES, PerkinElmer, Optima 2000DV, USA). The concentration of fluoride ion was analyzed by the ion selective electrode (Orion ionplus 9609BN, Thermo Electron Corp., USA) and ion meter (PCM 700, Thermo Electron Corp., USA). Field emission scanning electron microscope (FE-SEM, JSM-6700F, JEOL, Japan) was carried out for microstructure observation of the solid phase.

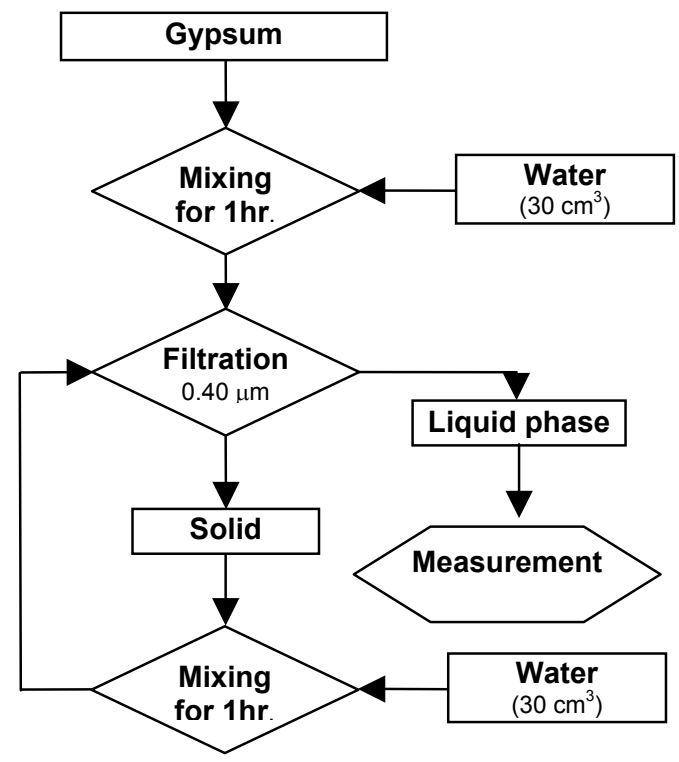

Figure 2: Schematic diagram of experimental procedure in this study. 


\subsubsection{Dissolving behaviour of gypsum in presence of carbon dioxide}

A schematic representation of the experimental apparatus used for the study of the dissolving behaviour of gypsum under a carbon dioxide atmosphere was shown in Figure 3. The mixture of gypsum sample and distilled water were put into a polypropylene bottle, $\mathrm{CO}_{2}$ gas was then aerated into the mixture and the $\mathrm{pH}$ was adjusted by adding $\mathrm{NaOH}$ solution. The amount of $\mathrm{NaOH}$ solution added was controlled by a pH controller (NPH-680D, Nisshin Rika Co. Ltd., Japan) with an applied $\mathrm{pH}$ electrode. The solid phase was analyzed by powder X-ray diffraction (Miniflex, Rigaku, Co. Ltd., Japan).

\section{Results and discussion}

\subsection{Leaching behaviour of gypsum in water}

The leaching behaviour of gypsum in water was investigated. $1.0 \mathrm{~g}$ of chemical gypsum samples were added to $30 \mathrm{~cm}^{3}$ of ultra-purified water and shaken for $1 \mathrm{hr}$. After shaking, solid phase was separated from mixture and added to water again. Figure 4 shows the microstructure of the chemical gypsum No.1 before (A in Figure 5) and after (B in Figure 5) leaching in water. In the photograph, water ground the surface, and rounded the corners of the gypsum particle. From the figure, impurities in the gypsum particles cannot be easily dissolved by water.

Figure 5 shows the concentration of fluoride in solutions after each repeat leaching. Fluoride is one of the impurities in chemical gypsum. From Figure 4, most of the fluoride in the chemical gypsum No. 1 (closed circles in the figure) dissolved at first leaching. However, fluoride concentration of the solution leached from chemical gypsum No. 2 (open circles in the figure) decreased slightly.
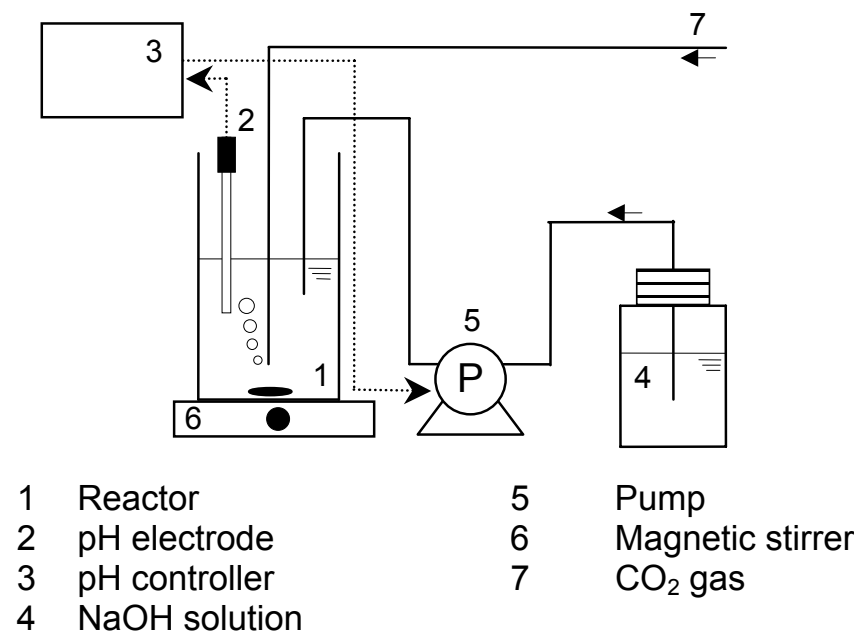

Figure 3: Experimental apparatus for study of dissolving behaviour of gypsum. 

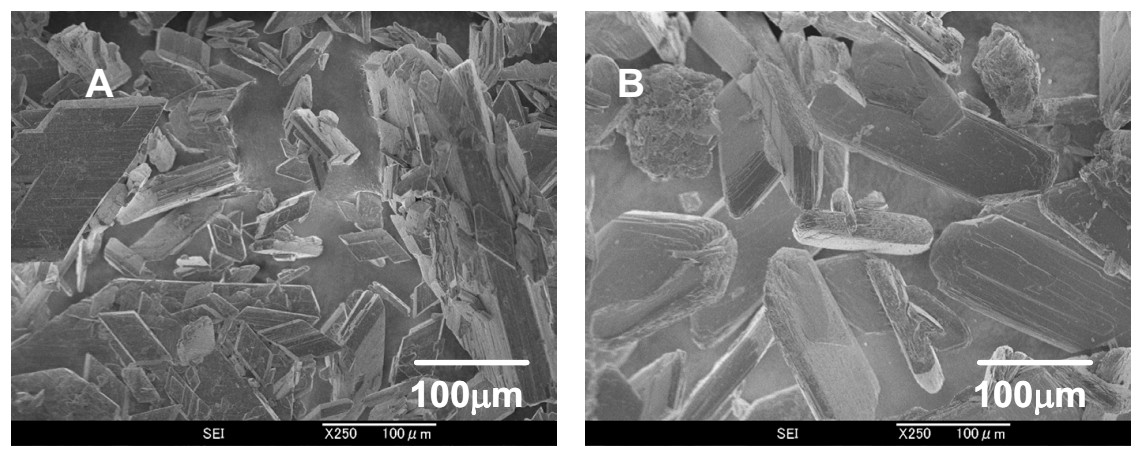

Figure 4: FE-SEM photographs of particles of chemical gypsum No. 1 before (A) and after (B) leaching test in water.

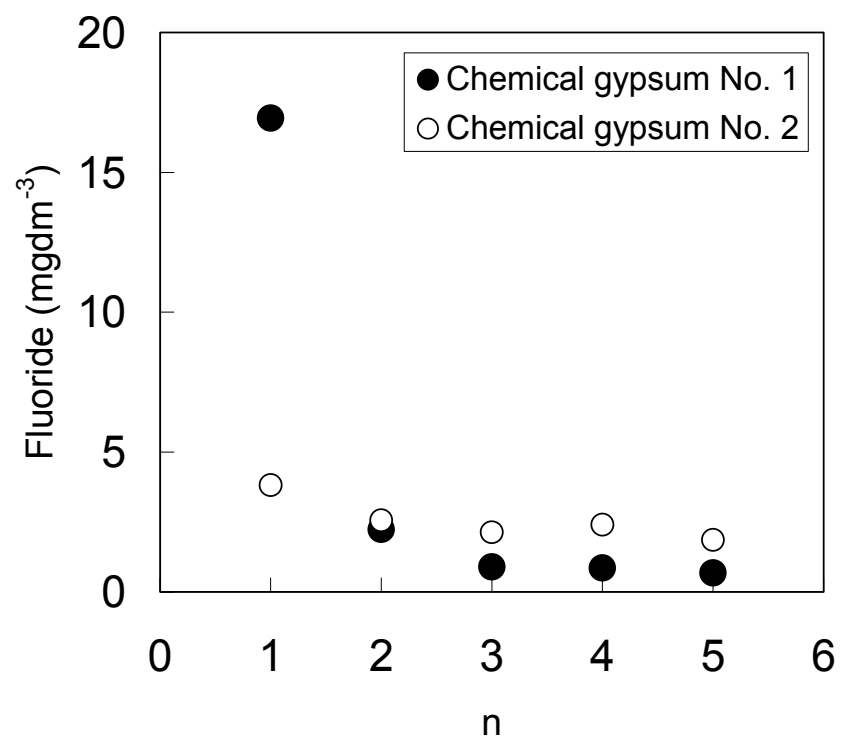

Figure 5: Fluoride concentration in the solutions after each repeat leaching test. \#n is number of repeat leaching.

From these results, most of the fluoride does not exist in the particle of chemical gypsum No. 1. Fluoride in chemical gypsum No. 1 can be easily removed by water. Therefore, fluoride of chemical gypsum No. 2 exists in particles, and cannot be easily removed by water.

\subsection{Dissolving behaviour of gypsum in the presence of carbon dioxide}

The dissolving behaviour of gypsum under a carbon dioxide atmosphere was investigated with $3.0 \mathrm{~g}$ of gypsum and $1.0 \mathrm{dm}^{3}$ of purified water set into a 
polypropylene bottle. $\mathrm{CO}_{2}$ gas was then aerated into the mixture for $12 \mathrm{hr} . \mathrm{pH}$ was adjusted by adding $\mathrm{NaOH}$ solution. Figure 6 shows powder X-ray diffraction patterns of gypsum (A in Figure 6) and solid phase in the mixture after experiment (B in Figure 6). From Figure 6, all of the gypsum dissolved and turn in to calcium carbonate. This result supports the previous experiment based on the chemical equilibrium described above. Similar results were obtained at alkaline $\mathrm{pH}$.

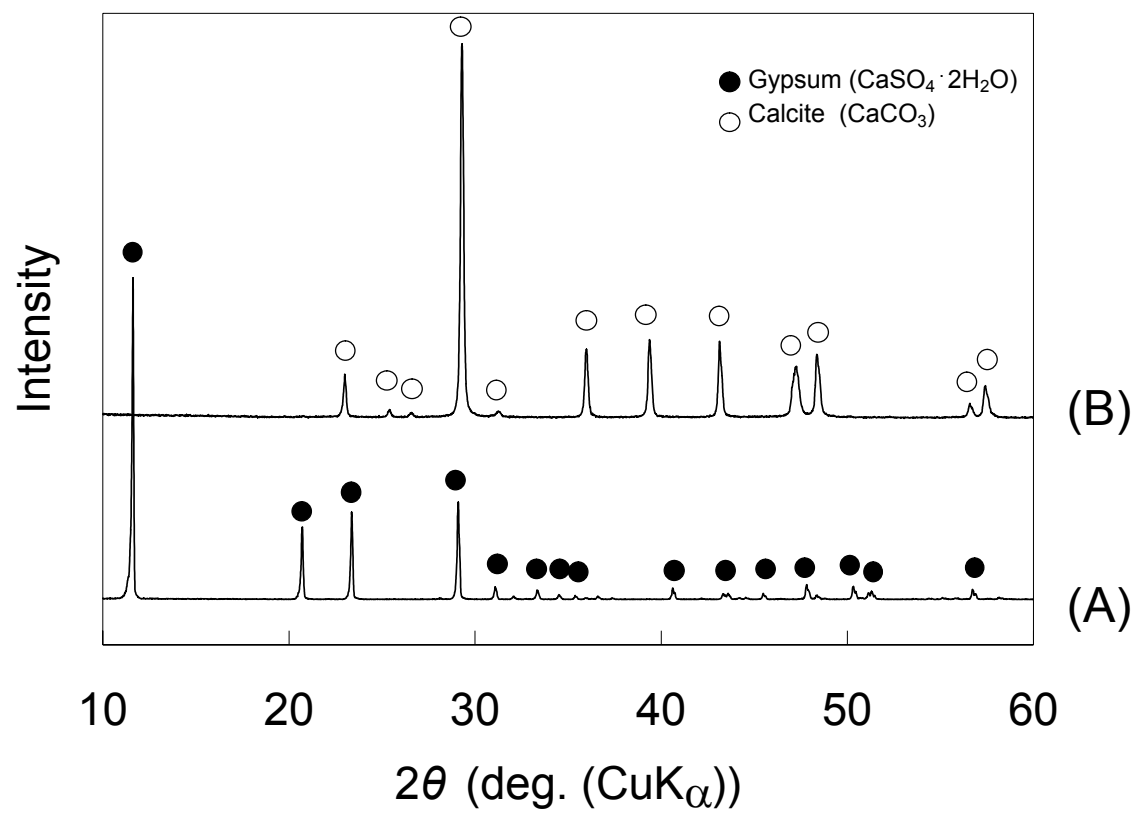

Figure 6: Powder X-ray diffraction patterns of (A) before and (B) after dissolving experiment of gypsum in presence of carbon dioxide.

\section{Summary}

In this study, we investigated the leaching behaviour of impurities in gypsum in the soil. The results demonstrated that impurities of gypsum might easily leach into the soil because gypsum dissolves and converts to calcium carbonate in a solution attached to higher partial pressure of carbon dioxide. The results obtained in this study are applicable to management of impurities of waste gypsum board in the roadbed.

\section{Acknowledgement}

This study was supported in part by a Waste Management Research Grant from the Ministry of the Environment, Japan (K1611, 1727). 


\section{References}

[1] Kaji, K. \& Tsuda, T., Fluoride and phosphate in the by-produced gypsum in phosphoric acid process. Gypsum Lime, 48, pp. 162-167, 1960.

[2] Corbridge, D.E.C., Phosphorous: An Outline of its Chemistry, Biotechnology and Technology (5 ${ }^{\text {th }}$ Ed.), Elsevier, Amsterdam, pp. 192193, 1995.

[3] C. Rinaudo, and M. Franchini-Angela, Gypsum crystallization from cadmium poisoned solutions. J. Cryst. Growth., 89, pp. 257-266, 1988

[4] Karberg, N.J., Pregitzer, K.S., King, J.S., Friend, A.L. \& Wood, J.R., Soil carbon dioxide partial pressure and dissolved inorganic carbonate chemistry under elevated carbon dioxide and ozone. Oecologia, 142, pp. 296-306, 2005

[5] Tafu, M \& Chohji, T., A method for estimating amounts of acid-soluble phosphate in carbonized activated sludge, J. Ecotech. Res., 12, in press, 2006. 